\title{
VENUS METHANE AND WATER
}

\author{
Thomas M. Donahue \\ Space Physics Research Lab, Department of Atmospheric, Oceanic and Space Sciences, University of Michigan \\ R. Richard Hodges, Jr. \\ Center for Space Studies, University of Texas at Dallas
}

\begin{abstract}
The Pioneer Venus Large Probe Neutral Mass Spectrometer collected data that apparently, but almost surely misleadingly, indicate the presence of a large amount of methane (1000 - $6000 \mathrm{ppm})$ in the atmosphere of Venus from $60 \mathrm{~km}$ to the surface. The measured ratio of $\mathrm{CH}_{3} \mathrm{D}$ to $\mathrm{CH}_{4}$ was about $5 \times 10^{-3}$. The ratio for Venus methane equilibrated with water would have been $9 \times 10^{-2}$ and for terrestrial methane $6 \times 10^{-4}$. Transfer of deuterium from atmospheric HDO to poorly deuterated methane can account for the strange gradient in the water vapor mixing ratio below $10 \mathrm{~km}$ previously reported. Similar deuterium transfer within the mass spectrometer causes reduction in the apparent ratio of $\mathrm{HDO}$ to $\mathrm{H}_{2} \mathrm{O}$. A full accounting for the deuterium atoms increases the ratio from 100 to 157 times terrestrial. This, in turn, leads to a revised value of $28 \mathrm{ppm}$, constant with altitude below $25 \mathrm{~km}$, for the mixing ratio of water vapor. Terrestrial methane mixed with $136 \mathrm{Xe}$ was introduced into the instrument for technical reasons and is the logical candidate for the source. But the methane detected, unlike ${ }^{136} \mathrm{Xe}$, closely mimics the behavior of an atmospheric gas. Despite this and the strange $\mathrm{D} / \mathrm{H}$ ratio, the arguments against this methane being purely atmospheric are overwhelming. A preferable, but not provable, explanation is that it was generated by a reaction between an unidentified highly deuterated atmospheric constituent and a poorly deuterated instrumental contaminant.
\end{abstract}

\section{The Observations}

The Pioneer Venus Large Probe Neutral Mass Spectrometer (LNMS) sampled 236 discrete mass settings between 1 and 208 amu instead of scanning continuously through the spectrum. In the device $\mathrm{CO}_{2}$ and other active gases were pumped by a chemical getter, while inert gases like $\mathrm{Ar}$ and $\mathrm{CH}_{4}$ follow a different flow path to a sputter ion pump. The instrument was designed to operate at constant ion source pressure by control of the pumping speed of $\mathrm{CO}_{2}$ and sequencing of the inlet leaks. Consequently, the instrumental response is not proportional to the external pressure, and the altitude profiles for $\mathrm{CO}_{2}$ and well mixed gases like Ar are very different. These instrumental issues are fully addressed by Hoffman et al. [1980a, 1980b]. The procedure for controlling precisely the setting of the discrete mass channels involved releasing methane and $136 \mathrm{Xe}$ inside the instrument. These gases were transported from Earth in the same container and flowed out from it through the same

Copyright 1993 by the American Geophysical Union

Paper Number 93GL00513

0094-8534/93/93GL-00513\$03.00 plumbing into the LNMS. In the forms of $136 \mathrm{Xe}^{+}$, ${ }^{136} \mathrm{Xe}^{++}, \mathrm{CH}_{4}{ }^{+}, \mathrm{CH}_{3}{ }^{+}, \mathrm{H}^{+}, \mathrm{H}_{2}{ }^{+}$, and $\mathrm{H}_{3}{ }^{+}$, products of these marker gases were monitored at a large number of mass settings. Because of this deliberate contamination of the LNMS with terrestrial $\mathrm{CH}_{4}$ and its products, we refrained for a long time from attempting to extract information about methane and hydrogen as constituents of the atmosphere of Venus from the data. Eventually, however, in the hope of explaining the mysterious hydrogen deficit in the water vapor profile below $10 \mathrm{~km}$ found by the LNMS [Donahue and Hodges, 1992], we decided to examine carefully the 15,16 , 17, 2 and 3 amu data. When we did so we found (Figure 1) that, although the $136 \mathrm{Xe}$ count rate remained stable within the expected range of variation throughout the descent, as it always had during pre-flight and post-flight laboratory simulations, the count rates for $\mathrm{CH}_{4}$ and all its progeny jumped by about 30 percent as soon as the two entrance leaks to the LNMS were opened. They then increased steadily as the probe descended, except for a sharp drop at the time the inlet leaks were plugged by sulfuric acid droplets at $51 \mathrm{~km}$. The counting rates for $\mathrm{CH}_{4}$ and related species remained at a level of about 35 times that of the well mixed gas ${ }^{36} \mathrm{Ar}$ down to $50 \mathrm{~km}$. The higher conductance microleak was valved off at $47 \mathrm{~km}$. The rates increased after the remaining leak opened at $26 \mathrm{~km}$ to about 210 times mass 36 near $12 \mathrm{~km}$ and then decreased to about 100 times $36 \mathrm{Ar}$ at $0.9 \mathrm{~km}$, where the last full data set was acquired. The mixing ratio of $36 \mathrm{Ar}$ measured by the LNMS was $30 \pm{ }_{10}^{20} \mathrm{ppm}$. On the basis of a relative instrument sensitivity of $0.93 \pm 0.1$ for methane and

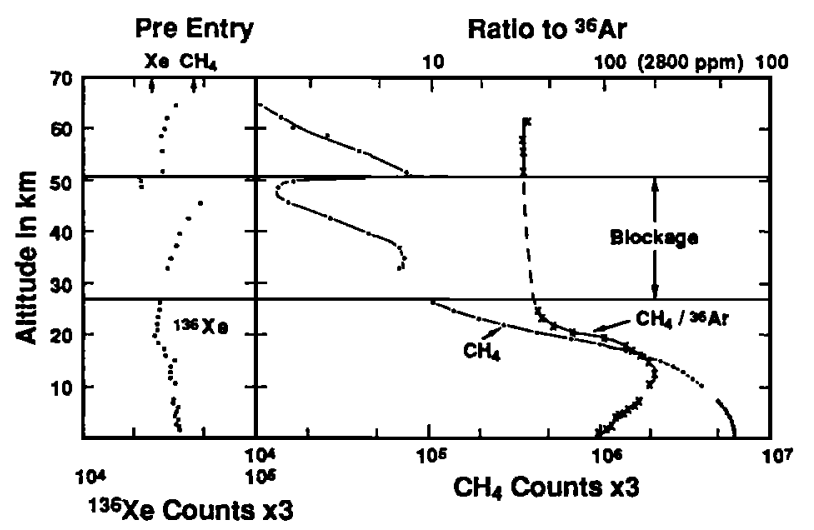

Fig. $1 \mathrm{CH} 4$ and ${ }^{136} \mathrm{Xe}$ counts per data frame multiplied by 3. The preentry $\mathrm{CH}_{4}$ count rate, corrected for the variation in calibration gas background exhibited by ${ }^{136} \mathrm{Xe}$, has been subtracted. A ratio of 100 to ${ }^{36} \mathrm{Ar}$ translates to a $\mathrm{CH}_{4}$ mixing ratio of $2800 \mathrm{ppm} / \mathrm{v}$. The increase in $136 \mathrm{Xe}$ counts near $47 \mathrm{~km}$ is related to the discharge of an isotope enrichment cell. 
argon the maximum mixing ratio of methane, if it is atmospheric, turns out to be $5900 \pm 200 \mathrm{ppm}$. Above $50 \mathrm{~km}$ the mixing ratio was $980 \mathrm{ppm}$ and near the surface $2800 \mathrm{ppm}$. The excess $\mathrm{CH}_{4}$ detected by the LNMS behaved like other atmospheric gases, such as $\mathrm{CO}_{2}$, the noble gases, $\mathrm{H}_{2} \mathrm{~S}$, $\mathrm{C}_{2} \mathrm{H}_{2}$, and $\mathrm{C}_{2} \mathrm{H}_{6}$, in that their counting rates all abruptly increased when the leaks were opened at $64 \mathrm{~km}$, then increased steadily as the probe descended until the leaks closed at $51 \mathrm{~km}$, whereupon they dropped sharply for several data frames, slowly recovered below $45 \mathrm{~km}$, and recommenced a rapid increase after the leak opened at $26 \mathrm{~km}$ (Figure 2).

There were LNMS channels at 17.002 and $17.026 \mathrm{amu}$. The first of these was sensitive, mainly, to $\mathrm{OH}$, and the signal in it tracked water vapor closely. The second was affected by both ${ }^{13} \mathrm{CH}_{4}(17.032 \mathrm{amu})$ and $\mathrm{CH}_{3} \mathrm{D}(17.037 \mathrm{amu})$. The ratio of the counts in the 17.026 channel to those in the 16.031 (mainly $\mathrm{CH}_{4}$ ) channel (Figure 3) was not constant with altitude. Before entry, the ratio was consistent with that expected for a mixture of isotopic species with terrestrial ratios of ${ }^{13} \mathrm{C} /{ }^{12} \mathrm{C}$ and $\mathrm{D} / \mathrm{H}$. We have decomposed the signal in the 17.026 channel into the contributions of ${ }^{13} \mathrm{CH}_{4}$ and ${ }^{12} \mathrm{CH}_{3} \mathrm{D}$, using the ${ }^{13} \mathrm{C} /{ }^{12} \mathrm{C}$ measurement of $1.10 \times 10^{-2}$ obtained from $\mathrm{CO}_{2}$ data to determine the ${ }^{13} \mathrm{CH}_{4}$ portion of the $17.026 \mathrm{amu}$ data; the method is similar to that described by Donahue and Hodges [1992]. This analysis yielded the $\mathrm{CH}_{3} \mathrm{D} / \mathrm{CH}_{4}$ values plotted in Figure 4. The average value of the ratio from the surface to $20 \mathrm{~km}$ is $(4.9 \pm 1.5) \times 10^{-3}$, where the uncertainty is almost all due to the procedure of subtracting the ${ }^{13} \mathrm{CH}_{4}$ contribution to the $17 \mathrm{amu}$ data. Above $20 \mathrm{~km}$ the ratio appears to increase to about $8 \times 10^{-3}$ at $26 \mathrm{~km}$, the altitude at which the sulfuric acid stoppage of the inlet leak was terminated. The terrestrial ratio would be $5.8 \times 10^{-4}\left(0.9 \times 2 \times 3.23 \times 10^{-4}\right)$, where 0.9 is a fractionation factor [Fegley and Treiman, 1992] and $3.2 \times 10^{-4}$ is the ratio of $\mathrm{HDO}$ to $\mathrm{H}_{2} \mathrm{O}$. On the basis of a Venus ratio of $5 \times 10^{-2}$ for $\mathrm{HDO}$ and $\mathrm{H}_{2} \mathrm{O}$, as deduced in the next section, the ratio expected for Cytherean methane would be $9 \times 10^{-2}$. The measured ratio is neither terrestrial nor Cytherean. Because of low count rates and inaccuracies in the subtraction process the statistics of the ratios obtained above $50 \mathrm{~km}$ are very

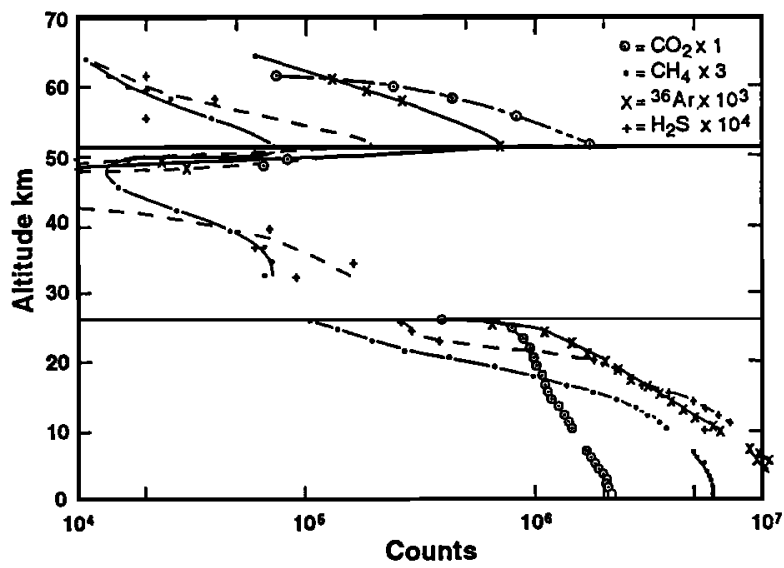

Fig. 2 Counts versus altitude for $\mathrm{CH}_{4}$ and a number of atmospheric species. One of the two microleaks was closed at about $45 \mathrm{~km}$. This accounts for the apparent discontinuity between count rates before and just after leak blockage.

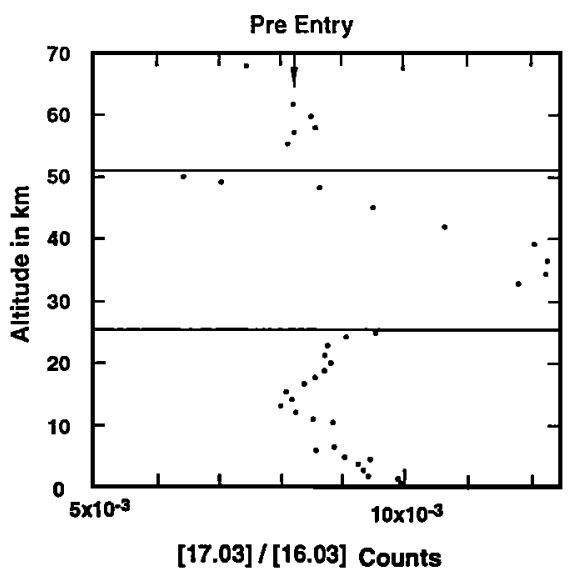

Fig. 3 Ratio of counts in the 17.03 to the counts in the 16.03 amu channel. 17.03 counts are due mainly to $\mathrm{CH}_{3} \mathrm{D}$ and ${ }^{13} \mathrm{CH}_{4}$.

poor. The difference between the measured ratio before entry and the value for terrestrial methane is not statistically significant.

\section{Transfer of D from HDO to $\mathrm{CH}_{4}$ : $\mathrm{D} / \mathrm{H}$ Revisited}

While the microleaks were covered with sulphuric acid droplets between $50.3 \mathrm{~km}$ and $26 \mathrm{~km}$ the counting rate for $\mathrm{CH}_{4}$ and $\mathrm{CH}_{3} \mathrm{D}$ dropped at first and slowly recovered in the fashion of other atmospheric species. The ratio of $\mathrm{CH}_{3} \mathrm{D}$ to $\mathrm{CH}_{4}$ did not remain constant during this period but rose from about $7 \times 10^{-3}$ to almost $10^{-2}$ before dropping again to about $8 \times 10^{-3}$ just before the leak reopened. The $\mathrm{CH}_{3} \mathrm{D}$ counting rate and the $\mathrm{CH}_{4}$ counting rate multiplied by $7 \times 10^{-3}$, are plotted in Figure 5, together with the difference between them. We believe that the "excess" $\mathrm{CH}_{3} \mathrm{D}$ counts near $37 \mathrm{~km}$ were probably produced by transfer of deuterium atoms to $\mathrm{CH}_{4}$ from the HDO in the LNMS. These transfer reactions could not have occurred in the gas phase. The partial pressures were too low. If our proposal is correct, the reactions must have occurred on instrumental surfaces, particularly in the getters. The suggestion of a hysteresis effect in the decay of the $\mathrm{CH}_{3} \mathrm{D}$ to $\mathrm{CH}_{4}$ ratio between $25 \mathrm{~km}$

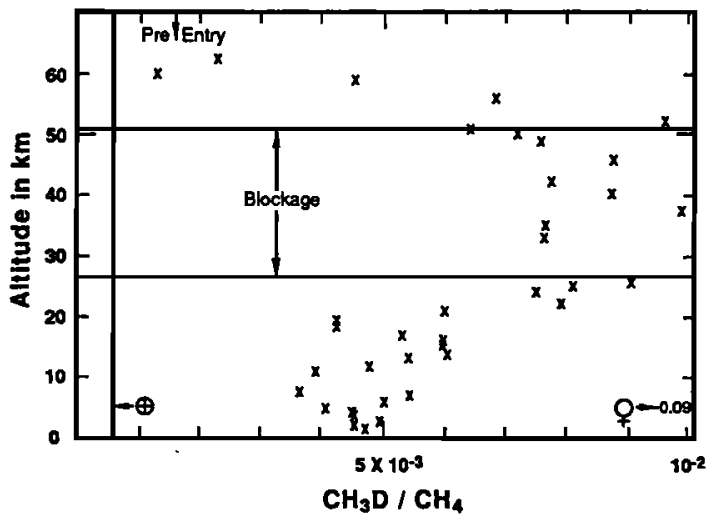

Fig. 4 Data in Fig. 3 with ${ }^{13} \mathrm{CH}_{4}$ contribution removed and corrected for offset of $\mathrm{CH}_{3} \mathrm{D}$ mass from the LNMS 16.03 mass setting. Terrestrial and equilibrium Venus ratios are indicated. 


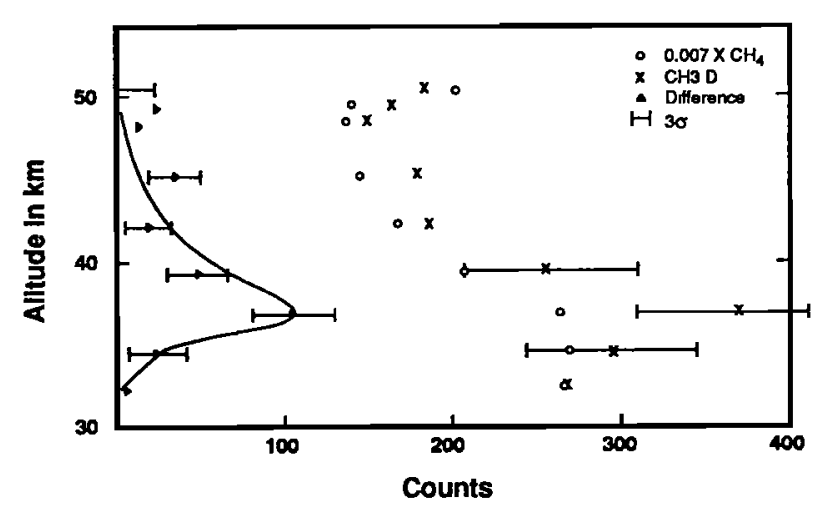

Fig. $5 \mathrm{CH}_{3} \mathrm{D}$ counts and $\mathrm{CH}_{4}$ counts multiplied by 0.007 during leak blockage. Rates are not corrected for preentry levels, thus represent total methane. The difference is attributed to enrichment of $\mathrm{CH}_{3} \mathrm{D}$ by HDO in the LNMS.

and $20 \mathrm{~km}$ is evidence in favor of this mechanism. If the excess deuterium in $\mathrm{CH}_{3} \mathrm{D}$ was derived from $\mathrm{HDO}$, our previous inventory of HDO [Donahue et al., 1982], made while the leak was closed, amounting to $225 \pm 30$ counts at its maximum, must be increased by $117 \pm 70$ counts to allow for the deuterium atoms lost by HDO molecules. Since the $\mathrm{H}_{2} \mathrm{O}$ count rate was 6800 at that time, our $\mathrm{HDO}$ to $\mathrm{H}_{2} \mathrm{O}$ ratio for Venus water in sulfuric acid droplets needs to be increased to $(5.0 \pm 1.0) \times 10^{-2}, 157$ times terrestrial, which does not disagree with $(3.8 \pm 1.2) \times 10^{-2}$ obtained by de Bergh et al. [1991].

\section{$\mathrm{H}_{2} \mathrm{O}$ Mixing Ratio Revised}

In turn this means that the analysis we presented of the $\mathrm{H}_{2} \mathrm{O}$ mixing ratio in the Venus atmosphere [Donahue and Hodges, 1992] must be revised downward by a factor of at least 1.5. We have also determined that the relative efficiency for production of $\mathrm{H}_{2} \mathrm{O}^{+}$and $\mathrm{Ar}^{+}$ions should be corrected from 3.1 [Lampe et al., 1957] to 1.6 [Rapp and Golden, 1965; Orient and Srivastava, 1987]. This reduces the mixing ratio of water vapor measured by the LNMS from 67 ppm to $28 \pm{ }_{5}^{18} \mathrm{ppm} / \mathrm{v}$. This result agrees with the recent analysis of a near IR spectrum [Pollack et al, 1992] which yields a mixing ratio of $30 \mathrm{ppm}$ below the clouds.

The transfer of deuterium atoms from $\mathrm{HDO}$ to $\mathrm{CH}_{4}$ that apparently occurred in the LNMS while the leaks were closed suggests that the same phenomenon could account for the deficiency in deuterated water detected by the mass spectrometer that we have interpreted as a decrease in $\mathrm{H}_{2} \mathrm{O}$ mixing ratio between $10 \mathrm{~km}$ and the surface [Donahue and Hodges, 1992]. This finding was based on the assumption that the $\mathrm{D} / \mathrm{H}$ ratio in $\mathrm{HDO}$ and $\mathrm{H}_{2} \mathrm{O}$ detected by the LNMS remained constant with altitude and equal to the ratio in the ambient atmosphere. If $425 \mathrm{HDO}$ molecules out of a total of 705 had exchanged deuterium for hydrogen with methane molecules at $0.9 \mathrm{~km}$ and a progressively smaller fraction up to $10 \mathrm{~km}$, the gradient in HDO would be accounted for. This requires an increase in the counting rate of $\mathrm{CH}_{3} \mathrm{D}$ near the surface of only 365 counts in 10000 , too small to be detectable. We suggest that this is what happened. The transfer could have occurred within the LNMS as well as outside it in the atmosphere -- given the evidence of transfer inside the LNMS that took place near $40 \mathrm{~km}$. Hence this proposed solution for the water vapor gradient problem does not depend on an actual encounter of the probe with deuterium-poor atmospheric methane.

We have found evidence for similar transfer of deuterium from deuterated hydrogen compounds in the case of hydrogen sulfide and ethane, both of which seem to be well mixed in the lowest $20 \mathrm{~km}$ of the atmosphere. In Figure 6, for example, the counting rate for $\mathrm{H}_{2} \mathrm{~S}$ is compared with that expected if its mixing ratio is $3 \mathrm{ppm}$. It appears that the mixing ratio is constant to about $20 \mathrm{~km}$ where the $\mathrm{H}_{2} \mathrm{~S}$ begins to disappear. Above $50 \mathrm{~km}$ its mixing ratio is only about 0.5 ppm. The counting rate for HDS is $5 \times 10^{-2}$ that of $\mathrm{H}_{2} \mathrm{~S}$ down to about $15 \mathrm{~km}$. Below $10 \mathrm{~km}$ it decreases to about 1.5 $\times 10^{-2}$ times the $\mathrm{H}_{2} \mathrm{~S}$ rate in a fashion quite like that of the decrease suggested for the $\mathrm{HDO} / \mathrm{H}_{2} \mathrm{O}$ ratio. We note that these data confirm, not only the postulated transfer of deuterium to methane, but also the $\mathrm{D} / \mathrm{H}$ ratio of $2.5 \times 10^{-2}$ for Venus hydrogen, albeit with very poor statistics.

\section{Discussion}

The methane observations have presented us with a puzzle for which we can offer no convincing solution. Methane cannot be a stable atmospheric constituent with no exoatmospheric source. Irreversible oxidation at high altitude with surely occur. Gas phase reactions in the lower atmosphere will limit its lifetime to ten years if

$$
\mathrm{kn} \geq 2.5 \times 10^{-9} \mathrm{~s}^{-1},
$$

where $\mathbf{k}$ is a two body rate constant and $\mathrm{n}$ is the density of a reaction partner. This condition would be satisfied by $k \geq 2.5$ $x 10^{-18} \mathrm{~cm}^{-3} \mathrm{~s}^{-1}$ if the reactant mixing ratio is only $1 \mathrm{ppt} / \mathrm{v}$. If $\mathrm{k}$ is $10^{-13} \mathrm{~cm}^{-3} \mathrm{~s}^{-1}$ the reactant mixing ratio can be as low as $3 \times 10^{-17}$. In our data we find evidence for ${ }^{35} \mathrm{Cl}$ and $37 \mathrm{Cl}$, with mixing ratios of $1.3 \times 10^{-7}$ and $3.3 \times 10^{-8}$ respectively, both well mixed below $25 \mathrm{~km}$. Cl efficiently transforms $\mathrm{CH}_{4}$ to $\mathrm{CH}_{3}$. Of course this chlorine may be produced in the ion source from $\mathrm{HCl}$, for example. Unfortunately, $\mathrm{HCl}$ at 36 and $38 \mathrm{amu}$ is hopelessly masked in the LNMS data by the argon isotopes.

Furthermore, there is a disabling constraint imposed by the requirement that the high $\mathrm{D} / \mathrm{H}$ ratio of Venus water be stable

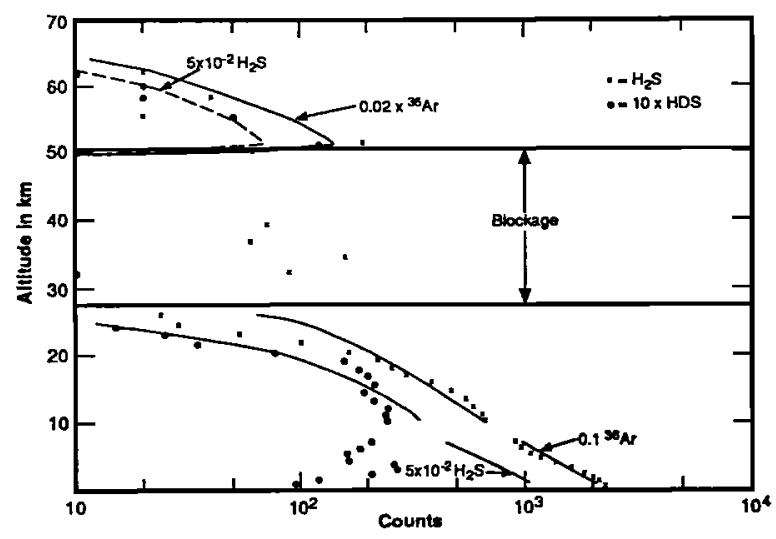

Fig. 6 Rates for $\mathrm{H}_{2} \mathrm{~S}$ and HDS compared to 0.1 times the $36 \mathrm{Ar}$ rate and $5 \times 10^{-2} \mathrm{H}_{2} \mathrm{~S}$ rate respectively. 
in the presence of such a large amount of deuterium poor methane. We know that the $\mathrm{D} / \mathrm{H}$ ratio did not change in the decade after the entry of the PV probe [de Bergh et al., 1991]. If the methane detected was atmospheric, its contributions to the atomic hydrogen inventory would have been $2.4 \times 10^{25}$ atoms $\mathrm{cm}^{-2}$. There are only $8.3 \times 10^{22} \mathrm{H}$ atoms $\mathrm{cm}^{-2}$ in Venus water, if the mixing ratio of water is $30 \mathrm{ppm}$. Only if the methane had been confined to a region covering less than $3.8 \times 10^{-4}$ of the surface of Venus $\left(4^{\circ} \times 4^{\circ}\right)$ would transfer of deuterium from $\mathrm{HDO}$ to $\mathrm{CH}_{4}$ have reduced the $\mathrm{D} / \mathrm{H}$ ratio in Venus water less than $10 \%$. Even though winds would transform such a methane plume into a continuous zonal band at high altitude in a short time, hitting such a plume and keeping the probe inside it from $60 \mathrm{~km}$ to the surface would be stunningly fortuitous. Furthermore, given that hydrogen escapes from the atmosphere with a flux of the order of $10^{7}$ $\mathrm{cm}^{-2} \mathrm{~s}^{-1}, 30$ million years would be required to rid the atmosphere of the hydrogen in one such injection.

Given that atmospheric methane cannot be the explanation the problem is to account for the strange $\mathrm{D} / \mathrm{H}$ ratio, the sudden increase in signal when the inlet leaks were opened, the decrease when they were sealed by sulfuric acid, and the large increase below $25 \mathrm{~km}$, all so very different from the behavior of the other marker gas $136 \mathrm{Xe}$. A suggestion more attractive than atmospheric methane is that we were observing methane generated by a reaction between a high $\mathrm{D} / \mathrm{H}$ atmospheric constituent and a low $\mathrm{D} / \mathrm{H}$ instrumental contaminant. Such a reaction could produce $\mathrm{CH}_{4}$ with a deuterium-hydrogen ratio intermediate between the Venus and terrestrial value. Unfortunately, we have no good candidate for the atmospheric constituent. None turned up at the 236 mass settings of the mass spectrometer, but possibly we jumped over the appropriate mass channel. Methane generating reactions that are not anaerobic and biological are not in standard catalogues of reactions. This interpretation, has the feature that it, unlike the one involving atmospheric methane, cannot be so completely discounted at this time and could be tested. But Occam's razor requires that a purely instrumental explanation exist. In the hope that it will eventually emerge, we feel obliged to publish these observations.

In any event, the positive consequences of this study are several. We have been able to offer an explanation for the puzzling apparent gradient in the mixing ratio of water vapor below $10 \mathrm{~km}$ to revise upward the deuterium - hydrogen ratio of Venus water vapor from 100 to 157 times terrestrial and to reduce our value for the mixing ratio of water vapor to 28 ppm, constant with altitude from $25 \mathrm{~km}$ to the surface. A $\mathrm{D} / \mathrm{H}$ ratio as large as reported here it can be attained in a steady state only if $\mathrm{D} / \mathrm{H}$ in the source of hydrogen is also large, even if the dominant hydrogen escape mechanisms discriminate strongly against deuterium. On the other hand, the tendency for Rayleigh fractionation of an ancient water reservoir to result in too large a ratio of $D$ to $H$ [Kumar et al. 1981] becomes a less serious problem, particularly if the escape mechanisms are not strongly fractionating.
Acknowledgements. We thank Mike Mumma for asking a revealing question, Don Hunten for a rigorous critique of our drafts and John Barker for chemical insights. This research was supported in part by grants from NASA.

References:

de Bergh, C., B. Bézard, T. Owen, D. Crisp. J.-P. Maillard, and B.L. Lutz, Deuterium on Venus: Observations from Earth, Science, 251, 547-549, 1991.

Donahue, T.M. and R.R., Hodges, Jr., Past and Present Water Budget of Venus, J. Geophys. Res., 97, 6083-6091, 1992.

Donahue, T.M., J.H. Hoffman, R.R. Hodges, Jr., and A.J. Watson, Venus Was Wet: A Measurement of the Ratio of Deuterium to Hydrogen, Science, 216, 630-633, 1982.

Fegley, Jr., B. and A.H. Treiman, Chemistry Of Atmosphere -- Surface Interactions On Venus And Mars, 7-71, Venus and Mars: Atmospheres, Ionospheres and Solar Wind Interaction,Geophys. Monograph, 66, 1992.

Hoffman, J.H., R.R. Hodges, T.M. Donahue, and M.B. McElroy, Composition of the Venus Lower Atmosphere From the Pioneer Venus Mass Spectrometer, J. Geophys. Res., 85, 7882-7890, 1980a.

Hoffman, J.H., R.R. Hodges, W.W. Wright, V.A. Blevins, K.D. Duerksen, and L.D. Brooks, Pioneer Venus Sounder Probe neutral gas mass spectrometer, IEEE Trans. Geosci. Remote Sens., GE-18, 80-84, $1980 \mathrm{~b}$.

Kumar, S., D.M. Hunten, J.B. Pollack, Nonthermal escape of hydrogen and deuterium from Venus and implications for loss of water, Icarus, 55, 369-373, 1985.

Lampe, F.W., J.L. Franklin, and F.H. Field, Cross sections for ionization by electrons, J. Chem. Phys., 79, 6129-6132, 1957.

Orient, O.J. and S.K. Srivastava, Electron impact ionization of $\mathrm{H}_{2} \mathrm{O}, \mathrm{CO}, \mathrm{CO}_{2}$ and $\mathrm{CH}_{4}, J$. Phys. B: At. Mol. Phys., 20, 3923-3936, 1987.

Pollack, J., J.B. Dalton, D. Grinspoon, R.B. Wattson, R.Freedman, D. Crisp, D.A. Allen, B. Bézard, C. de Bergh, Near-infrared light from Venus' nightside a spectroscopic analysis, Bull. Am. Astron. Soc., 24, 996, 1992.

Rapp, D. and P. Englander-Golden, Total Cross sections for ionization and attachment in gases by electron impact, I, Positive ionization, J. Chem. Phys., 43, 1464-1479, 1965.

T.M. Donahue, University of Michigan, Space Physics Research Lab, Department of Atmospheric, Oceanic and Space Sciences, Ann Arbor, MI 48109-2143.

R. Richard Hodges, Jr., University of Texas at Dallas, Center for Space Sciences, P.O. Box 688, Richardson, TX 75083-0688.

(Received: November 10, 1992

Revised: January 13, 1993

Accepted: February 23, 1993) 